\title{
A framework for implementing and sustaining a curricular innovation in a higher education midwifery programme
}

\author{
C N Nyoni, BSc Hons Nursing Science, MSoc Sc Nursing, PhD; Y Botma, PhD \\ School of Nursing, Faculty of Health Sciences, University of the Free State, Bloemfontein, South Africa
}

Corresponding author: C N Nyoni (nyonic@ufs.ac.za)

\begin{abstract}
Background. A competency-based curriculum was adopted for a 1-year post-basic midwifery programme in a small African country with a high maternal and neonatal mortality ratio. Two years after nation-wide implementation, disparities in the enactment of the curriculum were observed within and across the nursing education institutions (NEIs). Such disparities were attributed to lack of a framework in implementing the new curriculum, which jeopardised sustainability of the entire competency-based midwifery programme. A framework for implementing and sustaining a curricular innovation in a higher education midwifery programme was developed.

Objective. To develop and validate a framework for implementing and sustaining a curricular innovation in a higher education midwifery programme. Methods. A multiple-methods research design was used to develop the framework, guided by the theory-of-change logic model. This design was executed in three sequential but interrelated phases, inclusive of an integrative review, a gap analysis of the implementation of the programme and a frameworkdevelopment process. Primary implementers from all NEIs in the setting validated the developed framework through discussion and consensus.

Results. A framework for implementing and sustaining a curricular innovation in a midwifery programme was developed. It reflects an integration of evidence obtained from research and expertise from primary implementers of the curriculum.

Conclusions. Designing a strategy for higher education institutions (HEIs) for implementing and sustaining curricular innovations should be based on an interplay of empirical evidence and contextual realities. HEIs should identify challenges related to curriculum implementation, and recommend tailor-made approaches that are based on evidence. Primary implementers of the curriculum are fundamental in enhancing the validity and feasibility of such a strategy within their setting.
\end{abstract}

Afr J Health Professions Educ 2019;11(3):96-100. https://doi.org/10.7196/AJHPE.2019.v1 1i3.1153

Higher education institutions (HEIs) responsible for training midwives need to transform their education programmes to align with the changing educational landscape. ${ }^{[1,2]}$ Such transformations should focus on the development of competent midwives who have a positive influence on maternal and neonatal mortality indicators, driven by a cutting-edge curriculum.

The curriculum is seen as a multi-layered phenomenon encompassing the espoused curriculum, the enacted curriculum and the experienced curriculum. ${ }^{[3]}$ Changes in the needs of society influence HEIs to innovate their espoused curriculum ${ }^{[4,5]}$ through the introduction of new learning outcomes, new teaching and assessment methods and even different pedagogical values. ${ }^{[6]}$ Failure to promote the implementation of such curricular innovations may result in curricular drift, which Woods $s^{[5]}$ describes as the difference between the espoused curriculum and the enacted curriculum. The outcome of curriculum drift may be dire, because envisaged outcomes in the espoused curriculum, such as the development of competent midwives, may not be realised.

The context of the study reported in this article was a competency-based curriculum $(\mathrm{CBC})$ for a 1-year midwifery programme, developed and implemented for the first time in 2014 in the kingdom of Lesotho. The adoption of a CBC was aimed at producing midwives who have a positive influence on the perennially high maternal and neonatal mortality indicators. The maternal mortality ratio in Lesotho is 487 deaths per 100000 live births, which is above the global average of 216 deaths per 100000 live births. ${ }^{[2]}$
The CBC replaced a teacher-centred content-driven hospital-based curriculum, which had been in place for many years. The new curriculum was underpinned by constructivism as a learning theory ${ }^{[7]}$ and fused with other educational principles, such as scaffolding, ${ }^{[8]}$ authenticity and constructive alignment. ${ }^{[9]}$ It was also aligned with the national policy of primary healthcare, which is the pregnant woman's first point of contact with healthcare services. Implementing the CBC resulted in a need for a different set of administrative, teaching and learning skills from primary stakeholders. These skills included the development of student-centred learning material, new assessment approaches, integration of evidencebased practice, simulation-based education and placement of students in the community.

However, within 2 years of a nationwide implementation, the authors became aware of disparities in the enactment of the $\mathrm{CBC}$ in and among the nursing education institutions (NEIs), which threatened the sustainability of the entire competency-based midwifery programme. These disparities included the adoption of previous teaching approaches and assessment practices not aligned with the new curriculum, and students verbalising a lack of support during learning. These were evidenced in minutes of meetings, interaction with primary stakeholders and results of programme accreditation from the Council on Higher Education (CHE) in Lesotho. Stakeholders in the NEIs reflected on the lack of a framework for implementing the new curriculum as a contributing factor to the disparities in enactment of the CBC. 
Through multiple-methods research executed in three phases, we developed a framework for implementing and sustaining a curricular innovation for the midwifery programme in Lesotho. This article presents the framework as validated by primary implementers from NEIs in Lesotho. We argue that insights into the development of a sustainable strategy for implementing and sustaining a curricular innovation could guide higher education midwifery programme renewal for more effective education.

\section{Methods}

The framework was developed through a multiple-methods approach underpinned by the theory-of-change logic model. ${ }^{[10]}$ Three separate but interrelated studies were performed in the development of this framework. The initial study synthesised strategies used to sustain curricular innovations in higher education between 1996 and 2016 through an integrative review. The findings of this phase have been reported by Nyoni and Botma. ${ }^{[1]}$

The second study described the implementation of the competencybased midwifery programme in Lesotho. Primary stakeholders engaged in the implementation of the CBC, i.e. students $(n=48)$, educators $(n=11)$ and administrators $(n=16)$ from all NEIs $(n=5)$, were included in the study. Data were collected through individual interviews and focus group discussions. In addition to the narrative data, documents used in the programme were also captured. Data were analysed through both inductive and deductive reasoning against the International Confederation of Midwives (ICM) global standards for midwifery education. ${ }^{[1]}$ The study revealed the needs of primary stakeholders in relation to implementing the $\mathrm{CBC}$ in their institutions ${ }^{[12]}$ and factors influencing the implementation of the $\mathrm{CBC}$ in their midwifery programme. ${ }^{[13]}$

The third and final study was articulated in two sequential strands. The first strand involved researchers using the theory-of-change logic model to integrate the results of the first two studies to develop a framework. The second strand was a validation exercise of the developed framework by primary implementers $(n=13)$ of the $\mathrm{CBC}$ in midwifery from all the NEIs in Lesotho. These primary implementers of the curriculum were invited to a 1-day validation session led by the first author. During the session, the purpose of the study was presented, including approaches to validating the framework. The primary implementers discussed the framework, based on its specific headings, in small groups. Each group presented the outcomes of their discussion, which were either confirmed or rejected by the entire group. Consensus was reached based on feasibility and reasoning.

\section{Ethical approval}

Ethical approval for the study was granted by the Health Sciences Research Ethics Committee of the University of the Free State (ref. no. HSREC 22/2017) and the Institutional Research and Ethics Committee of the Ministry of Health in Lesotho (ref. no. ID 25/2017). The framework for ethical educational research by Burgess and Cilliers ${ }^{[14]}$ underpinned the development and execution of the current study. The NEIs granted the researchers access to their institutions, and all individuals engaged in this study provided informed consent.

\section{Theoretical underpinning of the framework}

Logic models allow for the development of programmes, in this case a framework that links its intentions or objectives with the intended outputs, outcomes and foreseeable impact, inclusive of relevant processes. ${ }^{[10]}$ The
W K Kellogg Foundation explains that logic models allow for a visual presentation of how a particular programme or framework would work to reach its intended outcomes.

There are various types of logic models, but this study was nested in the theory-of-change logic model. It allowed the researchers to articulate clearly the problems related to implementing the $\mathrm{CBC}$ in the midwifery programme in Lesotho, describe the scope of needs and assets of the community of stakeholders implementing the $\mathrm{CBC}$, and acknowledge the factors that may influence implementation of the proposed framework. The model also allowed for the investigation of best practices as plausible solutions to the identified problems, including a statement of assumptions regarding why the selected strategies could work. The intended outcome of the framework is also described.

\section{Methodological integrity}

The validation exercise with the primary implementers of the $\mathrm{CBC}$ from all NEIs in Lesotho enhanced the credibility of the framework, while the integration of evidence from the literature strengthened its content validity. The nature of this developmental process was embedded in contextually based challenges, which limit the transferability of such a framework to any other setting, although an audit trail of the development of the framework may support other HEIs implementing a $\mathrm{CBC}$ in midwifery in sustaining their curriculum-change process.

\section{Findings}

This study resulted in the development of a framework for implementing and sustaining a curricular innovation in a midwifery programme in Lesotho (Fig. 1). The description of the framework includes the problem or issue, community needs and assets, strategies, influencing factors, assumptions and desired results.

\section{The problem or issue}

The validation exercise confirmed that NEIs struggled with implementing the curricular innovation of the $\mathrm{CBC}$, which threatened the sustainability of the entire competency-based midwifery programme. ${ }^{[13]}$ Accreditation results from a local higher education regulatory body affirmed this finding, as only one programme from one NEI was fully accredited.

\section{Community needs and assets}

The primary implementers validated the suggested community needs and were able to add other assets available in their NEIs. The community needs and assets are presented in accordance with the ICM global standards for midwifery education: ${ }^{[1]}$ organisation and administration; midwifery faculty; student body; the curriculum, including teaching and learning; resources; and assessment.

With regard to organisation and administration, primary implementers validated the need for independence of institutions from hospital boards, full accreditation of their programmes by the CHE, leadership in their programmes, and strengthening and redesigning of their partnerships with stakeholders who have a direct influence on the midwifery programme, such as government. The primary implementers acknowledged that the funding from government, availability of education partners, accreditation standards and support from the CHE were assets within the NEIs.

On the standard of midwifery faculty, the primary implementers agreed that, at the time of this research, there was a need for development of all 


\section{Research}

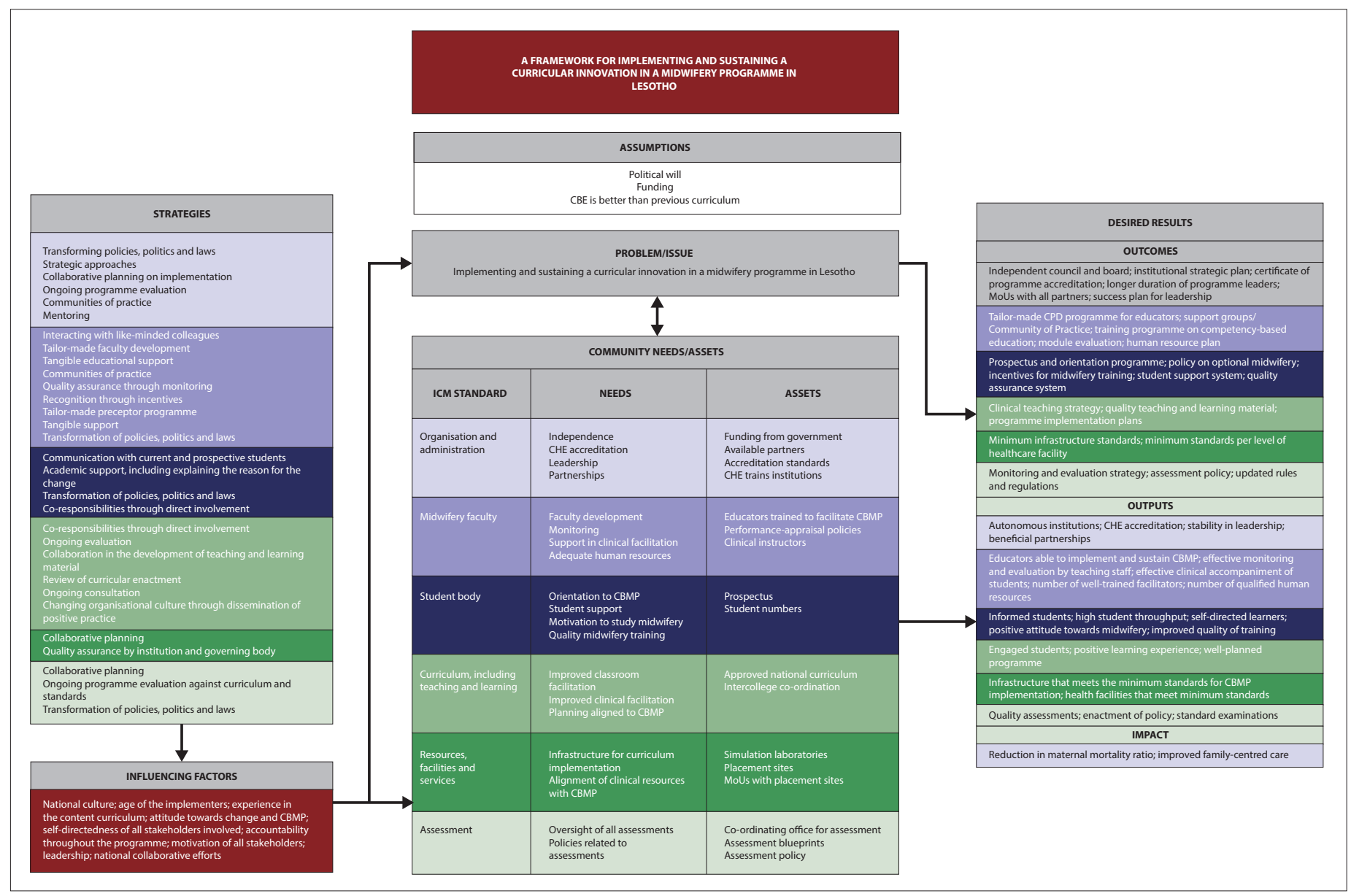

Fig. 1. A framework for implementing and sustaining a curricular innovation in a midwifery programme in Lesotho. (CBMP = competency-based midwifery programme; $C B E=$ competency-based education; ICM = International Confederation of Midwives; CHE = Council on Higher Education; MoUs = memoranda of understanding; $C P D=$ continuing professional development.)

educators in the programme in relation to implementing a CBC. The need for mentoring of educators, support in clinical facilitation and adequate human resources were also supported by the primary implementers. They further acknowledged the presence of educators with expertise in the $\mathrm{CBC}$, who could support others. Performance-appraisal policies were also realised as an asset, while some institutions had full-time clinical instructors for midwifery students, which would support the implementation of the $\mathrm{CBC}$ when mentored.

Students are expected to manifest curriculum goals at the end of their education. Primary implementers acknowledged the need for student orientation programmes into the $\mathrm{CBC}$, student support, including strategies to motivate them to study midwifery, and enhancing the quality of midwifery training. The primary implementers reflected that institutions had prospectuses and were guaranteed of students every year.

With regard to the standard of the curriculum, which included teaching and learning, primary implementers validated the need for improved classroom facilitation, improved clinical facilitation, and programme planning to align with the $\mathrm{CBC}$. An approved $\mathrm{CBC}$ and platform for NEIs to meet and discuss the curriculum were reflected as assets.

The infrastructure for curriculum implementation and aligment of the clinical teaching resources to the $\mathrm{CBC}$ were validated by the implementers as needs with regard to the standard of resources and infrastructure. The primary implementers acknowledged support from the Nursing Education
Partnership Initiative (NEPI), which supported all NEIs with simulation laboratories and human birth simulators. The primary implementers also reflected that they had clinical platforms for training students; however, few institutions had any memoranda of understanding (MoUs) regarding such platforms. MoUs detail expected interactions between clinical platforms and NEIs, and can be tailor made to support the implementation of the CBC.

The assessment of learner competence in these NEIs lacked oversight, as there were no such policies in place. The primary stakeholders explained that the presence of a co-ordinating office for summative assessments, including assessment blueprints, was an asset within these NEIs.

\section{Strategies}

The primary stakeholders validated all strategies synthesised from the integrative review. ${ }^{[1]}$ These strategies were presented against the specific standards, as stipulated in the ICM global standards for midwifery education ${ }^{[1]}$ based on the needs and assets of NEIs. According to the integrative review and validation of primary stakeholders, the implementation of these strategies was intended to reflect interaction between students, educators and administrators in the NEIs in Lesotho.

\section{Influencing factors}

Influencing factors determine the utility of the framework, which were validated by the primary stakeholders informed by the second study. ${ }^{[13]}$ 
These factors comprised the culture and age of the implementers, their experience in the previous content-driven curriculum, and their attitude towards change. The level of self-directedness of all the stakeholders engaged with the programme, including accountability for and of the programme, had to influence the implementation of the framework. ${ }^{[13]}$ Leadership style was also included as an influencing factor.

\section{Assumptions}

The assumptions in this framework were based on descriptions by the authors and primary stakeholders. These assumptions are the political will, funding and belief that the $\mathrm{CBC}$ is better than the previous curriculum.

\section{Desired results}

The desired results reflect what was anticipated after implementing the framework. These were presented as three main criteria, i.e. outputs, outcomes and impact. The results were informed by the intentions of the $\mathrm{CBC}$, including the needs of the NEIs in Lesotho in relation to the competency-based midwifery programme as validated by the primary implementers.

Outputs are the direct products of activities of this framework, presented under each specific standard and aligned with the needs and assets of the NEIs. With regard to the standard of organisation and administration, the outputs are: independent councils and boards, institutional strategic plans, accreditation certificates, longer terms for the position of head of the midwifery programme, MoUs with all partners and succession plans for leadership. In terms of the standard of midwifery faculty, the outputs are: tailor-made continuing professional development (CPD) programmes for educators, a training programme on competency-based education for educators, module evaluation and a human resource plan. Outputs with regard to the student body are: a comprehensive prospectus and orientation programme for students, a policy on optional midwifery, incentives for midwifery training, a student support system and a quality-assurance system.

Outputs with regard to the standard of the curriculum are: a clinical teaching strategy, quality teaching and learning material and programme implementation plans. Infrastructure-related outputs are minimum criteria and standards for educational institutions and healthcare facilities. For the assessment standard, outputs are: updated rules and regulations for the midwifery programme, including a monitoring and evaluation strategy for assessments.

Outcomes included specific changes in the primary stakeholder's behaviour, knowledge, skills, status and level of functioning after interventions prescribed by the framework. From this framework, the desired outcomes were autonomous institutions with stable leadership and beneficial partnerships with all NEI stakeholders. Other desired outcomes were educators who are able to implement a competency-based midwifery programme. Consequently, students would be better informed regarding the programme and have a positive attitude towards midwifery as a discipline. Curriculum outcomes include a positive learning experience and quality assessments.

The desired impact of implementing this framework will be experienced in the long term, aligned with the reduction of maternal and neonatal mortality by family-centred care.

\section{Discussion}

A variety of factors influence the sustainability of curricular innovations in professional programmes in higher education. The curriculum is the fulcrum of professional programmes, and curriculum innovation directly influences all other aspects of the programme. Failure to adjust the various interrelated aspects of a professional programme during the implementation of curricular innovation may contribute to disparities in curricular enactment, setting the stage for curricular drift. ${ }^{[5]}$

Frameworks based on contextual realities have a significant influence on supporting HEIs in adjusting programme-related aspects for sustained curricular innovations as opposed to frameworks imported from external settings. Implementing a curriculum is largely influenced by contextual factors, which should be paramount in designing strategies used in sustaining professional programmes. ${ }^{[15]}$ Such strategies should be grounded in the experiences and expertise of primary implementers, who are able to relive contextual realities through designing feasible solutions. In this study, primary implementers provided valuable insight into validating components of a framework based on contextual realities around the implementation of a $\mathrm{CBC}$ in Lesotho. Bottom-up approaches to developing and validating frameworks for sustaining curricular innovations in programmes such as midwifery improve acceptance, further increasing the utility of such a framework. ${ }^{[16]}$

It is essential that frameworks designed to improve curricular innovation implementation within higher education be grounded in the espoused curricular goals and the standards used in establishing a professional programme. Such approaches allow for HEIs to respond to their original reason for curricular change, at the same time avoiding superficial evaluations, where curricular innovations may be branded as failure. In the current setting, the $\mathrm{CBC}$ document and the ICM global standards for midwifery education ${ }^{[1]}$ underpinned the inquiry and design of the framework for implementing and sustaining curricular innovation in the midwifery programme.

\section{Conclusions}

A variety of factors influence HEIs to introduce curricular innovations in professional programmes, such as midwifery. The implementation of such curricular innovations needs to be supported by contemporary frameworks based on contextual realities and experiences of primary implementers. These primary implementers provided expert opinion based on their experiences and realities within their context. Involving primary implementers in the development of such frameworks increases acceptance and buy-in.

Further research in this field should evaluate the effect of implementing such contextually designed frameworks on primary implementers and population outcomes.

Declaration. This article is based on a study done by CNN in partial fulfilment of his $\mathrm{PhD}$ thesis.

Acknowledgements. The authors acknowledge Dr R Albertyn for critical reviewing of the manuscript and Ms J Viljoen for language editing of the article. The heads of nursing education institutions in Lesotho are acknowledged for their role in allowing their educators, students and other administrators to be part of the study.

Author contributions. CNN: designed the study, collected and analysed the data and drafted the manuscript; YB: designed the study, analysed the data and drafted the manuscript.

Funding. None.

Conflicts of interest. None. 
1. International Confederation of Midwives (ICM). The global standards for midwifery education. 2014. http:// www.internationalmidwives.org/what-we-do/education-coredocuments/global-standards-education (accesse 16 June 2017).

2. United Nations Population Fund. State of the world's midwifery. 2014. http://www.unfpa.org (accessed 3 July 2019)

3. Prideaux D. Curriculum design. BMJ 2003;326(7383):268-270. https://doi.org/10.1136/bmj.326.7383.268

4. Wilson EA, Rudy D, Elam C, Pfeifle A, Straus R. Preventing curriculum drift: Sustaining change and building upon innovation. Ann Behav Sci Med Educ 2012;18(2):23-26. https://doi.org/10.1007/BF03355202

5. Woods A. Exploring unplanned curriculum drift. J Nurs Educ 2015;54(11):641-644. https://doi. org/10.3928/01484834-20151016-05

6. Markee N. Managing Curricular Innovation. Cambridge: Cambridge University Press, 1997.

7. Amineh RJ, Asl H. Review of constructivism and social constructivism. J Soc Sci Lit Lang 2015;1(1):9-16,

8. Brunner J. Vygotsky: A historical and conceptual perpective. In: Weitsch V. Culture, Communication and Cognition: Vygotskyan Perspective. Cambridge: Cambridge University Press, 1985.

Cognition: Vygotskyan Perspective. Cambridge: Cambridge University Press, 1985.
9. Biggs J. Enhancing teaching through constructive alignment. High Educ1996:32(3):347-364. https://doi. 9. Biggs J. Enhancing teaching
org $/ 10.1007 / \mathrm{BF} 00138871$

10. W K Kellogg Foundation. Logic Model Development Guide, 2004. https://www.wkkf.org:443/resource-directory/ resource/2006/02/wk-kellogg-foundation-logic-model-development-guide (accessed 1 November 2016).
11. Nyoni CN, Botma Y. Strategies to sustain curricular innovations in higher education: An integrative review. roceedings of the 2017 South African Association of Health Educationalist Conference, 26 - 28 June 2017 Potchefstroom, South Africa.

12. Nyoni CN, Botma Y. Implementing a competency-based midwifery programme in Lesotho: A gap analysis Nurse Educ Pract 2019;34:72-78. https://doi.org/10.1016/j.nepr.2018.11.005

13. Nyoni CN, Botma Y. Sustaining a newly implemented competency based-midwifery programme in Lesotho: Emerging issues. Midwifery 2018;59:115-117. https://doi.org/10.1016/j.midw.2018.01.015

14. Burgess T, Cilliers F. A framework for ethical educational research: Principles and application. 2016. http://www healthedu.uct.ac.za (accessed 16 June 2017).

15. Reis S. Curriculum reform: Why? What? How? and how will we know it works? Isr J Health Policy Res 2018;7(1):30. https://doi.org/10.1186/s13584-018-0221-4

16. Collins SE, Clifasefi SL, Stanton J, et al. Community-based participatory research (CBPR): Towards equitable involvement of community in psychology research. Am Psychol 2018;73(7):884-898. https://doi.org/10.1037/
intions amp0000167

Accepted 1 July 2019 